\title{
Vowel-contingent feature detection
}

\author{
PETER HOWELL \\ University College, London, WCIE 6BT, England
}

\begin{abstract}
Do vowel-contingent selective adaptation effects for place of articulation depend on vowel identity, or on the particular formant frequencies used? An experiment is reported here which tested the adaptation effects of consonants with exactly the same formant transitions before different diphthongs. In this experiment, the phonetic identity of the vowel and the formant frequencies of the consonant are not confounded as they have been in previous studies. In the contingent adaptation condition, no phoneme boundary shifts were observed, and this is interpreted along with previous evidence for such phoneme boundary shifts when phonetic identity of the vowel and formant frequencies are confounded as indicating that adaptation operates on the spectral representation of the stimulus. Other evidence consistent with this conclusion is that adaptation with alternating adaptors from each end of the test series produced negligible shifts, and that a single adaptor from a diphthong series different from that of the test series produced phoneme boundary shifts as large as those with a single adaptor from the same test series.
\end{abstract}

There is considerable evidence that the cues for consonants in consonant-vowel syllables vary greatly depending on the vowel context. For example, /d/ before $/ \mathrm{i} / \mathrm{has}$ a rising second-formant transition while $/ \mathrm{d} /$ before $/ \mathrm{u} /$ has a falling second-formant transition. The formant transitions are not invariant cues for the place of articulation of stop consonants, and they contain information about the following vowel. Evidence has been presented to show that at least a syllable-length representation is available in auditory memory so as to take advantage of the spreading of cues over syllabic or greater length segments (Howell, 1978). This leaves open the question of how the cues for consonants are extracted from this representation. One proposal that has been made is that there are feature detectors which detect the cues for consonants contingent on the vowel environment (Cooper, 1974a). Feature detection which takes place contingent on the vowel environment requires a set of feature analyzers for every environment that a consonant occurs in. This makes the theoretical utility of such feature detectors suspect and the problem is exaggerated by contingent effects which occur for syllable position (Ades, 1974) and for the speech of different speakers (Ades, 1977). The present paper reports an experiment designed to evaluate the evidence presented in support of vowelcontingent feature detectors.

The present work constitutes part of a $\mathrm{PhD}$ thesis. The work was supported by the S.R.C. I would like to express my thanks to Professor R. J. Audley and S. M. Rosen for encouragement. Part of this work was reported at the 21st Tagung Arbeitender Psychologen, Heidelberg, April 1979, and the Ninth International Congress on Phonetic Sciences, Copenhagen, August 1979. Assistance towards traveling to these conferences was made available by the Tregaskiss fund of the University of London.
The technique employed by Cooper (1974a) to gain evidence for vowel-contingent feature detectors was the adaptation paradigm first employed by Eimas and Corbit (1973). The technique can be illustrated by considering synthetic speech sounds which vary in place of articulation. Spectral analysis reveals a number of cues which contribute to the perceived place of articulation of a particular stop consonant. These include the frequency of a brief noise burst and the second and third formant starting values (Liberman, Cooper, Shankweiler, \& Studdert-Kennedy, 1967). Two-formant synthetic voiced speech sounds varying only in the onset of the second formant transition are identified as consonants varying in place of articulation from bilabial to alveolar (/b-d/). A stimulus from the low-frequency end of this continuum is heard as /b/ before /ae/. Gradually increasing the second formant transition starting value leads to an abrupt change from $/ b /$ to $/ d /$ report at the point of changeover, which is called the phoneme boundary. Repeated presentation of a stimulus from one end of this continuum to which the subject does not have to respond (adaptation) gives a shift in the phoneme boundary towards the adapting stimulus. The original interpretation of this type of result was that opponent feature detectors exist which respond to features at each end of the continuum, and repeated presentation of an end stimulus selectively fatigues the feature detector at that end. This, in turn, results in the observed phoneme boundary shifts.

An issue that has received considerable attention in the adaptation literature and is pertinent to the evidence cited in support of the existence of vowelcontingent feature detectors is whether feature detectors operate at an auditory and/or phonetic 
level. One line of evidence cited to support the view that the level of processing modified by adaptation is sensitive to auditory rather than phonetic descriptions is the fact that phoneme boundary shifts are observed when stimuli derived from synthetic speech sounds (nonspeech adaptors) are used as adaptors (Tartter \& Eimas, 1975, and other references in Ades; 1976, review). For example, Tartter and Eimas (1975) presented parts of the speech signal as adaptors (e.g., the second formant alone) and found that these were sufficient for adaptation.

The presence of adaptation effects when the adaptor and test series are acoustically very different (Diehl, 1975; Ganong, Note 1) had suggested to some authors that the adaptors might affect the phonetic level as well (see also Cooper's, 1975, review). For example, Diehl (1975) studied adaptation on a /be$\mathrm{d} \varepsilon /$ continuum. He adapted with burst-cued cognates $(/ \mathrm{p} \varepsilon /$ or $/ \mathrm{t} \varepsilon /)$ and tested with a transition-cued series (cognates have the same place of articulation but differ in voicing). Phoneme boundary shifts on the place dimension were obtained even though the adaptor and test series were signaled by different cues to place. This result suggests a level of analysis at which information about bursts and formant transitions are integrated. The phonetic level is a plausible candidate. But Blumstein, Stevens, and Nigro (1977) have suggested an integrated acoustic property detector which is sensitive to both bursts and transitions.

If feature detection takes place contingent on the vowel environment, then adaptation with a consonantvowel syllable should be more effective when the vowel is shared with the test series than when it is not. Cooper (1974a) measured base-line performance on /ba-pa/ and /bi-pi/ continua. He then chose adaptors which varied in both voicing and vowel environment $(/ \mathrm{da} /$ and $/ \mathrm{ti} /)$. Adaptation consisted of an alternating sequence of these adapting stimuli (three of one, then three of the other) for $1 \mathrm{~min}$ (about 50 presentations of each). If vowel-contingent feature detectors exist, /da/ should shift the /ba-pa/ boundary towards $/ \mathrm{ba} /$ and $/ \mathrm{ti} /$ should shift the /bi-pi/ boundary towards /pi/. If voicing is extracted for the phoneme segment $(+V$ or $-V)$, then an alternating sequence of $/ d /$ and $/ t /$ should adapt each of the voicing detectors. The expected result, if the opposing shifts are summed, would then be negligible phoneme boundary changes. The presence of phoneme boundary shifts to the end which had the same vowel as the test series supported the vowel-contingent feature detector hypothesis. The results have been substantially confirmed by Miller and Eimas (1976), Sawusch and Pisoni (1978) and Pisoni, Sawusch, and Adams (Note 2). It is necessary to sound a note of caution because Pisoni et al. did not find significant shifts on the /bi-pi/ continuum although the boundaries had moved in the expected direction.
It may be noted that when the vowels are the same, the spectral overlap between the endpoint consonant of the test series and adapting stimuli is obviously the same, but when the vowels of the adaptors are different, there is less spectral overlap between the endpoint consonant of the test series and the adaptors. An alternative explanation of Cooper's (1974a) result is that consonant adaptation takes place at a level of processing sensitive to details of the auditory representation of the stimulus, and when there is less spectral overlap between the consonant of the adaptor and the test stimuli, there is less adaptation. This explanation has been proposed by Ades (1976), who considered vowel-contingent feature detectors unparsimonious.

The present paper reports an experiment designed to cancel the possible contributions of both phonetic and auditory sites of adaptation on a voiced stop consonant series and to assess any residual vowelcontingent effects. In order to hold spectral information in the consonant constant irrespective of vowel environment, exactly the same formant transitions were used to cue each consonant before different vowel segments. The diphthongs /au/ and /eI/ were used because they can have their formant transitions starting at the same value before different consonants (Howell, 1978).

A /b-d/ continuum was used for the test series and adaptors. Four adaptation conditions were employed in the experiment. First the $/ b /$ and the /d/ endpoint stimuli of each test series were used as the adaptors to demonstrate that these stimuli do produce standard adaptation effects (same series adaptor). In the contingent adaptation condition, the adaptors consisted of one endpoint stimulus from each test continuum, paired with a stimulus from the other end of the consonant continuum with the other diphthong appended to it (adaptors from both series). To determine whether adaptation occurs at all when the stimuli are not from the same series, the adaptation effects of single adaptors were assessed on a test series with a different diphthong (different series adaptor). In the final condition, both endpoint stimuli of each test series were used as adaptors to see whether their adaptation effects canceled out (adaptors from same series).

If vowel-contingent feature detectors exist, phoneme boundary shifts are expected in the condition with adaptors from both series. If spectrally specific feature detectors are responsible, then negligible shifts are expected in this condition, because the consonants from the ends of the continuum are presented equally often. If spectral position determines the amount of adaptation measured, then, since there are no differences in the consonants whether these are used as adaptors on the same or a different series, as much shift is expected whether an adaptor is from the same or a different test series. 


\section{METHOD}

\section{Subjects}

Four subjects (three female and one male) aged between 21 and 27 years were employed for 14 sessions. They attended on different days, except for one subject, who performed two sessions on 1 day. The subjects were recalled for four further sessions.

\section{Stimuli}

The consonant portion of each stimulus lasted $40 \mathrm{msec}$ and the diphthong for $100 \mathrm{msec}$. For all stimuli, the first formant rose linearly from 175 to $700 \mathrm{~Hz}$ over the first $40 \mathrm{msec}$, then decreased linearly to $380 \mathrm{~Hz}$ in the the $100 \mathrm{msec}$ of the diphthong. The second formant starting frequencies ranged in $100-\mathrm{Hz}$ steps from 1,200 to $1,800 \mathrm{~Hz}$, giving seven different starting values on the place dimension. The second formant transitions all approached $1,500 \mathrm{~Hz}$ linearly in the first $40 \mathrm{msec}$. The second formant transitions of the diphthongs decreased from 1,500 to $1,020 \mathrm{~Hz}$ (for $/ \mathrm{au} /$ ) or increased to $1,940 \mathrm{~Hz}$ (for $/ \mathrm{eI} /$ ), in the final $100 \mathrm{msec}$.

Each of the consonants could be paired with each diphthong, giving 14 stimuli in all. They were synthesized using a software parallel formant synthesizer running on a PDP-12 computer. The stimuli were synthesized at a constant fundamental frequency of $120 \mathrm{~Hz}$, and the relative amplitude of the first and second formants was the same. The stimuli were output at $8 \mathrm{kHz}$ and filtered at $3.5 \mathrm{kHz}$ before recording on a Revox tape recorder. The stimuli were presented to the subjects over headphones at a soundpressure level of approximately $75 \mathrm{~dB}$.

\section{Conditions}

Endpoint stimuli from the two series were used as adaptors. The appropriate adaptor or pair of adaptors for the four conditions outlined in the introduction were chosen. Further subconditions were given by counterbalancing which end of the consonant series was employed and on which diphthong series subjects were tested. All of the conditions and subconditions are presented in Table 1. Each subject received all of these, but in different random orders.

The subjects were recalled to perform the different series adaptor condition again; this was exactly the same as that performed previously, except that there were only 27 repetitions of the adaptor. This was done to determine whether 27 repetitions would give adaptation effects and whether measured adaptation increased with number of repetitions of the adaptor.

\section{Sequences}

Test sequences consisted of a randomization of 10 repetitions of each of the seven stimuli to determine the preadaptation

Table 1

Conditions Employed in the Experiment

\begin{tabular}{|c|c|c|c|}
\hline No. & Test Series & Adaptor(s) & Designation \\
\hline $\begin{array}{l}1 \\
2 \\
3 \\
4\end{array}$ & $\begin{array}{l}\text { /bau/-/dau/ } \\
/ \text { bel/-/del/ }\end{array}$ & $\begin{array}{l}\text { /bau/ } \\
\text { /dau/ } \\
\text { /bel/ } \\
\text { /deI/ }\end{array}$ & Same series adaptor \\
\hline $\begin{array}{l}5 \\
6 \\
7 \\
8\end{array}$ & $\begin{array}{l}\text { /bau/-/dau/ } \\
\text { /bel/-/deI/ }\end{array}$ & $\begin{array}{l}\text { /bau/ and /del/ } \\
/ \mathrm{dau} / \text { and /bel/ } \\
/ \mathrm{beI} / \text { and /dau/ } \\
/ \mathrm{del} / \text { and /bau/ }\end{array}$ & Adaptors from both series \\
\hline $\begin{array}{r}9 \\
10 \\
11 \\
12\end{array}$ & $\begin{array}{l}\text { /bau/-/dau/ } \\
/ \text { bel/-/deI/ }\end{array}$ & $\begin{array}{l}\text { /bel/ } \\
\text { /del/ } \\
\text { /bau/ } \\
\text { /dau/ }\end{array}$ & Different series adaptor \\
\hline $\begin{array}{l}13 \\
14\end{array}$ & $\begin{array}{l}\text { /bau/-/dau/ } \\
\text { /beI/-/deI/ }\end{array}$ & $\begin{array}{l}\text { /bau/ and /dau/ } \\
\text { /bel/ and /deI/ }\end{array}$ & Adaptors from same series \\
\hline
\end{tabular}

phoneme boundaries. The subjects responded by writing their responses. The interstimulus interval was $1 \mathrm{sec}$. In those conditions with one adaptor, the subjects heard the adaptor 54 times; in conditions with two adaptors, each stimulus was presented 27 times. When two adaptors were presented, the subjects heard one stimulus three times and then the other three times until they had received all presentations of the adaptors (following Cooper, 1974a). The interval between adaptors was $500 \mathrm{msec}$. The subjects then received seven randomly selected test stimuli before the adaptor was presented again. The subjects wrote the response again. This procedure was repeated until the subjects had classified each of the seven stimuli 10 more times.

\section{RESULTS}

The data from the different adaptation conditions are presented in Figure 1. The solid lines represent the preadaptation categorizations, and the dashed lines the categorization functions after adaptation with the labeled adaptor. The preadaptation categorizations were combined when there were two conditions which were the same, except for the consonant(s) of the adaptor(s), giving 10 preadaptation categorization functions (including the preadaptation categorization of the different series adaptor with 27 repetitions). The categorization curves were fit by cumulative normal functions using maximum likelihood (Bock \& Jones, 1968). This test, also known as probit analysis, weights the observations with respect to the reliability it is possible to achieve for that number of observations and with respect to their position in the distribution. From these lines, the $50 \%$ point or phoneme boundary and the standard error of the estimate were estimated. With these statistics, analysis proceeded by transforming the parameters to standard normal deviates. Onetailed tests were used throughout. The estimated phoneme boundaries with $95 \%$ confidence limits are presented in Figure 2. Four of the five preadaptation categorization functions of the /eI/ series are at higher values than those of the /au/. However, when the estimates of the phoneme boundaries and standard errors are pooled for each of the series and compared, there is no significant difference between the estimates for the /eI/ and /au/ series $(Z=1.27)$.

To determine whether standard adaptation effects are obtained for these stimuli, the phoneme boundary shifts of the same series adaptors were examined. Repeated presentation of one of the end-consonant stimuli shifts the phoneme boundary of the test series towards its end of the test continuum. A summary table of this and other statistical tests performed on this experiment is presented in Table 2.

Contingent adaptation effects are assessed by determining whether phoneme boundary shifts occur for the conditions with the different series adaptors. The phoneme boundary shifts when an alternating sequence of consonants from opposite ends of the two test series are presented are not significant.

Single adaptors from a different series to that tested 
SAME SERIES ADAPTOR
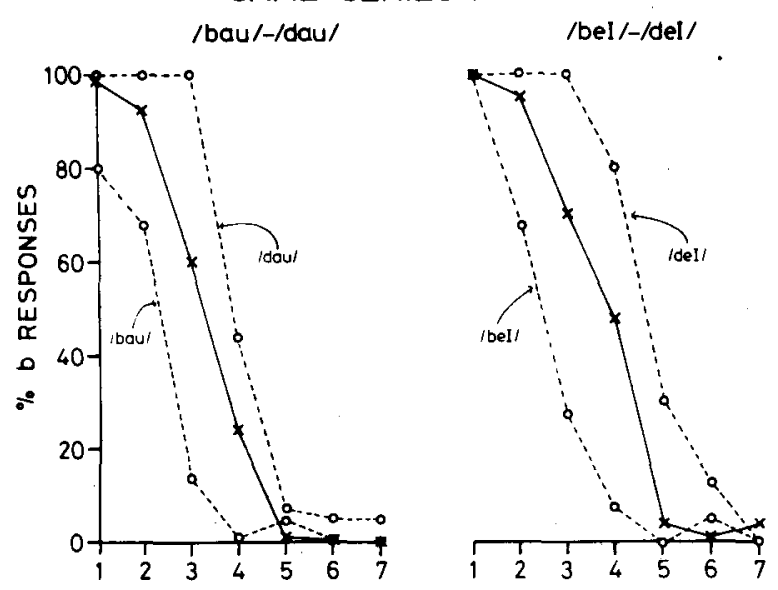

\section{DIFFERENT SERIES ADAPTOR}

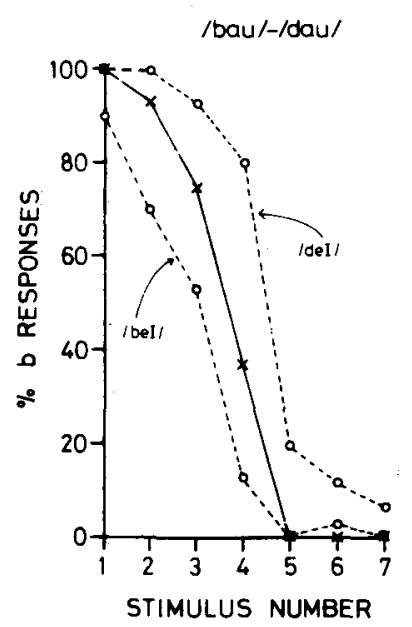

ADAPTORS FROM BOTH SERIES
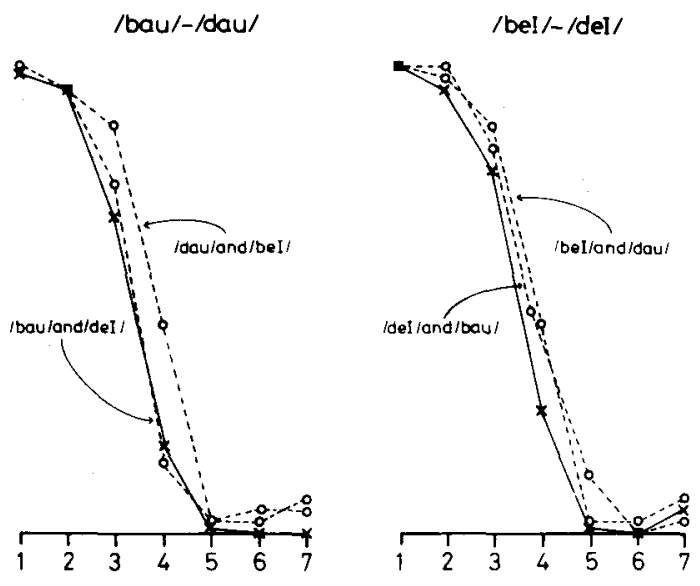

ADAPTORS FROM SAME SERIES
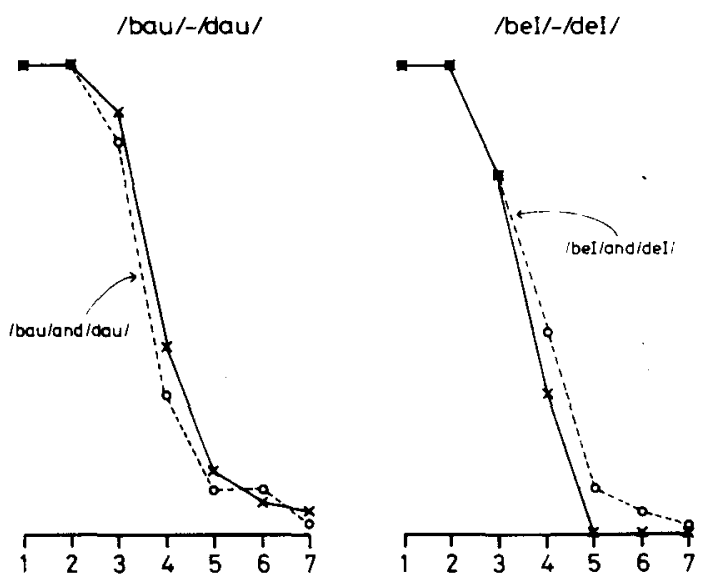

Figure 1. Classification of the stimuli before and after adaptation. The test series is given above each inset, and the postadaptation points (dashed line) are labeled with the appropriate adaptor.

give significant phoneme boundary shifts whether 54 or 27 repetitions of the adaptor are presented, except for 27 repetitions of a /bau/ adaptor on a /beI-deI/ series. A comparison of the phoneme boundary shifts with 54 or 27 repetitions indicates no difference in the size of the shifts. The conditions with 27 repetitions effect for the /bau-dau/ series and $100.7 \%$ for the /beI-deI/ series. The lack of phoneme boundary shifts in the contingent adaptation condition does not appear to be due to the smaller number of repetitions of the adaptor in that condition not being sufficient to fatigue the detectors.

Comparisons of the effectiveness of a particular adaptor when it is employed on the same or a different series shows no difference whether the series correspond or not. Thus the adaptor is equally effective whether it is adapted with the same or a different series.

\section{DISCUSSION}

The presence of phoneme boundary shifts with one adaptor from the same continuum as the test series may be interpreted as indicating that feature detectors for place of articulation exist. This result has been reported by other authors (e.g., Cooper, 1974b). This result and the finding of phoneme boundary shifts when an adaptor with a different diphthong from the test series might be accounted for by auditory or phonetic feature detectors, because the auditory features have a direct correspondence to the phoneme percept. To demonstrate adaptation at the phonetic level, it is necessary to show adaptation effects when the adaptor and test series differ and have no simple invariant acoustic relationship.

In the present experiment, an adaptor is as effective whether it is employed on its own or a different 


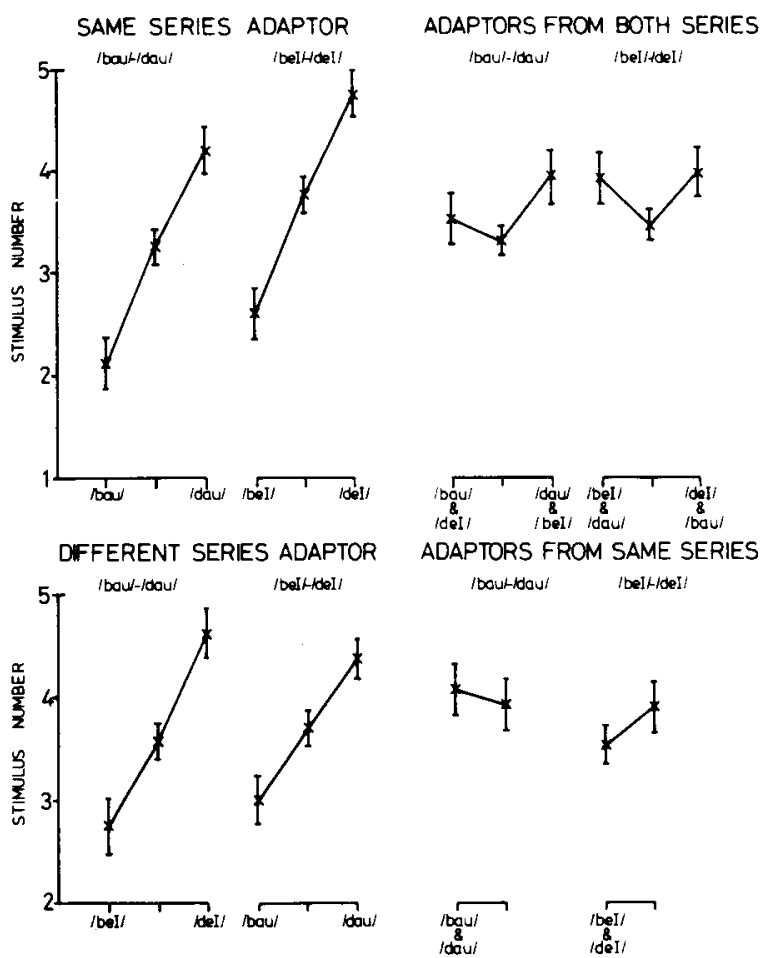

Figure 2. Phoneme boundaries and $95 \%$ confidence limits. Phoneme boundaries preadaptation are the nonlabeled points, and for the conditions where an adaptor is used, the adaptor used is given at the foot.

diphthong series. Thus, the transfer across vowel environments is $100 \%$ and suggests that the basis of the effect may be the spectral level. The amount of adaptation measured on a consonant series should be complete if, as in the stimuli employed here, stimuli with different vowels but the same formant transitions cueing the consonants (complete spectral overlap in the consonant transitions) are employed.

Adapting both ends of the place continuum either with adaptors from both ends of the same diphthong series or one from each end of the two series gives no significant phoneme boundary shifts. If vowelcontingent feature detectors exist, the different series adaptors should have adapted in the direction appropriate to the consonant which shared the diphthong with the test series. Taken in conjunction with the apparent evidence for vowel-contingent feature detectors reported by other authors, the present failure to obtain contingent adaptation is best explained by feature detectors which extract spectral information about formant transitions, independent of the identity of the following vowel. Previous reports of vowel-contingent selective adaptation effects can best be explained by the formant frequency specific nature of selective adaptation for place of articulation (Bailey, 1975). The consonants in previous experiments demonstrating vowel-contingent selective adaptation are conveyed by formant transitions at different frequencies. When consonants are defined by the same formant transitions, no contingent adaptation effects are observed.

The explanation of the present results is in partial agreement with that of Sawusch and Pisoni (1978). Their experiment was designed to discriminate between two mechanisms which could produce contingent adaptation effects. They argued that if both the stimuli that were used as adaptors determined performance, then adaptation would be taking place at a level where both vowels were represented and contingent adaptation might have a spectral basis. If only the adapting stimulus with the same vowel as the test series determined adaptation performance, then consonants on different vowels might be analyzed by different feature detectors. Their results were interpreted as indicating that performance is better predicted by the adaptor which shares the vowel with the test series for the voiced series but that both adaptors influence performance for the voiceless series. The present experiment has been interpreted as indicating that both adaptors influence performance for a voiced series. However, the summed performance for the voiced series in the Sawusch and Pisoni (1978) experi-

Table 2

Summary of the Statistical Tests Performed in the Experiment

\begin{tabular}{|c|c|c|c|c|c|c|c|c|c|c|}
\hline Test Series & Adaptor & $\mathrm{z}$ & Test Series & Adaptor & $\begin{array}{l}54 \text { reps } \\
\mathrm{z}\end{array}$ & $\begin{array}{c}27 \text { reps } \\
z\end{array}$ & Adaptor & $\begin{array}{l}\text { Same } \\
\text { Series }\end{array}$ & $\begin{array}{l}\text { Different } \\
\text { Series }\end{array}$ & z \\
\hline \multicolumn{3}{|c|}{ Same Series } & \multicolumn{4}{|c|}{ Adaptors from Same Series } & \multirow{2}{*}{\multicolumn{4}{|c|}{$\begin{array}{l}\text { Comparison of phoneme boundaries } \\
\text { before adaptation with those of a } \\
\text { single adaptor on the two series before } \\
\text { adaptation }\end{array}$}} \\
\hline \multirow[t]{2}{*}{$\begin{array}{l}\text { /bau-dau/ } \\
\text { /bau-dau/ } \\
\text { /beI-deI/ } \\
\text { /beI-deI/ }\end{array}$} & $\begin{array}{l}\text { /bau/ } \\
\text { /dau/ } \\
\text { /bel/ } \\
/ \text { deI/ }\end{array}$ & $\begin{array}{l}2.39^{*} \\
2.10^{* *} \\
2.42^{*} \\
2.23^{* *}\end{array}$ & $\begin{array}{l}\text { /bau-dau/ } \\
\text { /beI-deI/ }\end{array}$ & $\begin{array}{l}\text { /bau and dau/ } \\
\text { /beI and deI/ }\end{array}$ & $\begin{array}{l}.29 \dagger \\
.78 \dagger\end{array}$ & & & & & \\
\hline & Both Series & \multicolumn{5}{|c|}{ Adaptors from Different Series } & & & & \\
\hline $\begin{array}{l}\text { /bau-dau/ } \\
\text { /bau-dau/ } \\
\text { /beI-deI/ } \\
\text { /beI-deI/ }\end{array}$ & $\begin{array}{l}\text { /bau and del/ } \\
\text { /dau and beI/ } \\
\text { /bel and dau/ } \\
\text { /deI and bau/ }\end{array}$ & $\begin{array}{l}.53 \dagger \\
1.43 \dagger \\
1.02 \dagger \\
1.12 \dagger\end{array}$ & $\begin{array}{l}\text { /bau-dau/ } \\
\text { /bau-dau/ } \\
\text { /beI-deI/ } \\
\text { /beI-deI/ }\end{array}$ & $\begin{array}{l}/ \mathrm{beI} / \\
/ \mathrm{deI} / \\
/ \mathrm{bau} / \\
/ \mathrm{dau} /\end{array}$ & $\begin{array}{l}1.78^{* *} \\
2.42^{*} \\
1.73^{* *} \\
1.75^{* *}\end{array}$ & $\begin{array}{l}2.40^{*} \\
1.87^{* *} \\
1.26 \dagger \\
2.07^{* *}\end{array}$ & $\begin{array}{l}\text { /bau/ } \\
\text { /dau/ } \\
\text { /bel/ } \\
\text { /deI/ }\end{array}$ & $\begin{array}{l}\text { /bau-dau/ } \\
\text { /bau-dau/ } \\
\text { /beI-deI/ } \\
\text { /beI-deI/ }\end{array}$ & $\begin{array}{l}\text { /beI-deI/ } \\
\text { /beI-deI/ } \\
\text { /bau-dau/ } \\
\text { /bau-dau/ }\end{array}$ & $\begin{array}{r}1.14 \dagger \\
.42 \dagger \\
.26 \dagger \\
.24 \dagger\end{array}$ \\
\hline
\end{tabular}

*Significance level $=.01$ 
ment is not significantly worse than performance predicted on the basis of the adaptor with the same vowel as the test series for the voiced condition. A more parsimonious explanation of their results, which would be in line with the present results, is that contingent adaptation effects depend on both adaptors used in the experiment for the voiced and voiceless series.

Finally, the contribution of judgment artifacts needs to be considered. A traditional result of psychophysics is that if a psychophysical continuum, varying from, say, loud to soft, is presented for categorization, a stimulus that is classified as loud when a soft stimulus occurs more frequently may be classified as soft when a loud stimulus is presented more frequently. The technique which reveals this effect (manipulating the frequency of particular stimuli and referred to as anchoring) is formally similar to the adaptation paradigm where, as has been seen, the judgments are biased towards the adaptor too. Recent experiments show that anchoring effects occur for stop-consonant speech series (Diehl, Elman, \& McCusker, 1978; Simon \& Studdert-Kennedy, 1978). If, in the contingent procedure, the adaptors are anchoring each end of the continuum, then this could predict the observed results. This stands as a possible alternative explanation of the present results.

In summary, the present results show that vowelcontingent selective adaptation results are produced by detectors sensitive to the formant frequencies of stimuli, rather than by detectors sensitive to phonetic descriptions.

\section{REFERENCE NOTES}

1. Ganong, W. F. An experiment on 'phonetic adaptation.' Quarterly Progress Report, Research Laboratory of Electronics, M.I.T., 1975.

2. Pisoni, D. B., Sawusch, J. R., \& Adams, F. T. Simple and contingent adaptation effects in speech perception. Research on Speech Perception, 1975, 2, 22-55.

\section{REFERENCES}

Ades, A. E. How phonetic is selective adaptation? Experiments on syllable position and vowel environment. Perception \& Psychophysics, 1974, 16, 61-66.
AdEs, A. E. Adapting the property detectors for speech perception. R. J. Wales \& E. Walker (Eds.), New approaches to language mechanisms. Amsterdam: North Holland, 1976.

ADEs, A. E. Source assignment and feature extraction in speech. Journal of Experimental Psychology; Human Perception and Performance, 1977, 3, 673-685.

BAILEY, P. Perceptual adaptation in speech: Some properties of detectors for acoustical cues to phonetic distinctions. Unpublished doctoral thesis, University of Cambridge, Cambridge, England, 1975.

Blumstein, S. E., Stevens, K. N., \& Nigro, G. N. Property detectors for bursts and transitions in speech perception. Journal of the Acoustical Society of America, 1977, 61, 1301-1313.

Bock, R. D., \& Jones, L. V. The measurement and prediction of judgement and choice. San Francisco: Holden-Day, 1968.

COOPER, W. E. Contingent feature analysis in speech perception. Perception \& Psychophysics, 1974, 16, 201-204. (a)

Cooper, W. E. Adaptation of phonetic feature analyzers for place of articulation. Journal of the Acoustical Society of America, 1974, 56, 617-627. (b)

Cooper, W. E. Selective adaptation to speech. In F. Restle, R. M. Shiffrin, J. N. Castellan, H. Lindman, \& D. B. Pisoni (Eds.), Cognitive Theory. Hillsdale, N.J: Erlbaum, 1975.

DiEHL, $R$. The effect of selective adaptation on the identification of speech sounds. Perception \& Psychophysics, 1975, 17, 48-52.

Diehl, R., Elman, J. L., \& McCusker, S. B. Contrast effects on stop consonant identification. Journal of Experimental Psychology: Human Perception \& Performance, 1978, 4, 599-609.

Eimas, P. D., \& CoRB IT, J. D. Selective adaptation of linguistic feature detectors. Cognitive Psychology, 1973, 4, 99-109.

Howe LL, P. Syllabic and phonemic representations for short-term memory of speech stimuli. Perception \& Psychophysics, 1978, 24, 496-500.

Liberman, A. M., Cooper, F. S., Shankweiler, D. P., \& Studdert-Kennedy, M. Perception of the speech code. Psychological Review, 1967, 74, 431-461,

Miller, J. E., \& Eimas, P. D. Studies on the selective tuning of feature detectors for speech perception. Journal of Phonetics, $1976,4,119-127$.

Sawusch, J. R., \& Pisoni, D. B. Simple and contingent adaptation effects for place of articulation in stop consonants. Perception \& Psychophysics, 1978, 23, 125-131.

Simon, H. J., \& Studdert-Kennedy, M. Selective anchoring and adaptation of phonetic and nonphonetic continua. Journal of the Acoustical Society of America, 1978, 64, 1338-1357.

TARTTER, V.C., \& EimAs, P. D. The role of auditory and phonetic feature detectors in the perception of speech. Perception \& Psychophysics, 1975, 18, 293-298.

(Received for publication February 7, 1979; revision accepted October $8,1979$. 